\title{
Thoracic ectopic cordis in a nigerian child
}

\begin{abstract}
Ectopia cordis is derived from two Latin words which means outside and heart. It is a rare congenital malformation in which the heart is formed outside the thoracic cavity. The exact cause of ectopia cordis is unknown. The last documented report of a case of ectopic cordis in Nigeria was over two decades ago. Despite the challenging and limited health facility in the region, the current case survived until the seventh month of life. In view of its rarity, we discuss a case of thoracic ectopia cordis in a Nigerian child.
\end{abstract}

Keywords: ectopic, cordis, Nigerian, child
Volume 6 Issue 6 - 2016

\author{
Barakat Adeola Animasahun, 'Akpoembele D \\ Madise Wobo² \\ 'Associate Professor, Department of Paediatrics and Child \\ Health, Lagos State University College of Medicine, Nigeria \\ 2Senior Registrar, Department of Paediatrics Lagos State \\ University Teaching Hospital Ikeja, Nigeria
}

\section{Correspondence: Barakat Adeola Animasahun, Associate Professor, Department of Paediatrics and Child Health, Lagos State University College of Medicine, Lagos, Nigeria, Tel 2348037250264,Email deoladebo@yahoo.com}

Received: October 17, 2016 | Published: October 26, 2016
Core tip: Ectopia cordis is generally uncommon with few survivors. The previous report on ectopia cordis in Nigeria was two decades ago. Mortality from this condition is high. Prenatal ultrasound screening and fetal echocardiography can detect cases in-utero and further management plans instituted promptly although treatment options are limited. Management of ectopia cordis is extremely challenging with a few long term survivors even in the most advanced settings.

\section{Introduction}

Ectopia cordis is derived from two Latin words which means outside and heart. ${ }^{1}$ It is a rare congenital malformation in which the heart is formed outside the thoracic cavity. It occurs in 1 in 5-7 per 1,000,000 live births. ${ }^{2}$ It may occur as an isolated defect or in association with other body wall defects that affect the thorax, abdomen or both. ${ }^{3}$ It may also be associated with other intra cardiac lesions. ${ }^{4}$ Despite advances in cardiac surgery, ectopia cordis is extremely challenging with a few long term survivors even in the most advanced settings. ${ }^{4}$

The exact cause of ectopia cordis is unknown. The disorder has been largely attributed to abnormal development of the chest cavity. ${ }^{5}$ There are different types of ectopia cordis defined by the position of the heart outside the body. ${ }^{2,6}$ The thoracic subtype involves a partial or complete displacement of the heart outside the thoracic cavity through a sternal defect. We discuss in this paper, a case of thoracic ectopia cordis in a Nigerian child. The last documented report of a case of ectopic cordis in Nigeria was over two decades ago. Despite the challenging and limited health facility the patient survived until the seventh month of life.

\section{Case report}

The patient was a female infant admitted on the tenth day of life with a history of a defect in the upper third of the anterior chest wall noticed from birth and was referred to our facility at the Lagos State University Teaching Hospital (LASUTH) for specialist care. The baby was delivered to a 24years old primiparous woman. The pregnancy was planned and welcomed, supervised at private hospital and was not adversely eventful. Her mother took only routine prenatal multi-vitamins during pregnancy. There was no history of ingestion of herbal concoction or exposure to radiation. There was no history of previous spontaneous abortions. Her mother had one antenatal scan in first trimester which was reported to be essentially normal. The pregnancy was term and delivery was per vaginal at the same private hospital where she had antenatal care. Immediate delivery period was uneventful. Her birth weight was unknown. A defect was noticed on her anterior chest wall at birth. She is the first child of her parents. There was no history of consanguinity. Her father was a 29years old artisan who wields metals for a living.

General physical examination revealed a female infant who had a defect on her manubro-sternum with a pulsating heart covered by the pericardium visible through the defect. She was not pale, anicteric, afebrile with an admission weight of $3000 \mathrm{~g}$, length of $47 \mathrm{~cm}$ and head circumference of $35 \mathrm{~cm}$. There was no obvious dysmorphology. Oxygen saturation in room air was $98 \%$. Examination of the chest revealed a large defect measuring $5 \mathrm{~cm}$ by $5 \mathrm{~cm}$ over the manubrosternum exposing a pulsating heart covered by pericardium as shown in Figure 1. Her pulses were normal with normal heart rate. Other systemic exams were normal. An initial diagnosis of thoracic ectopia cordis was made.

Investigations done at various times in the course of her admission were plain chest radiograph, echocardiography, complete blood count, serum electrolytes and abdominal ultrasound scan. Roentgenogram of the chest revealed a clear lung field with mesocardium. Echocardiograph revealed a dextro-rotated heart with situs solitus, $2 \mathrm{~mm}$ Patent Ductus Arteriosus and a patent foramen ovale. The complete blood count, abdominal ultrasound and serum electrolytes were normal.

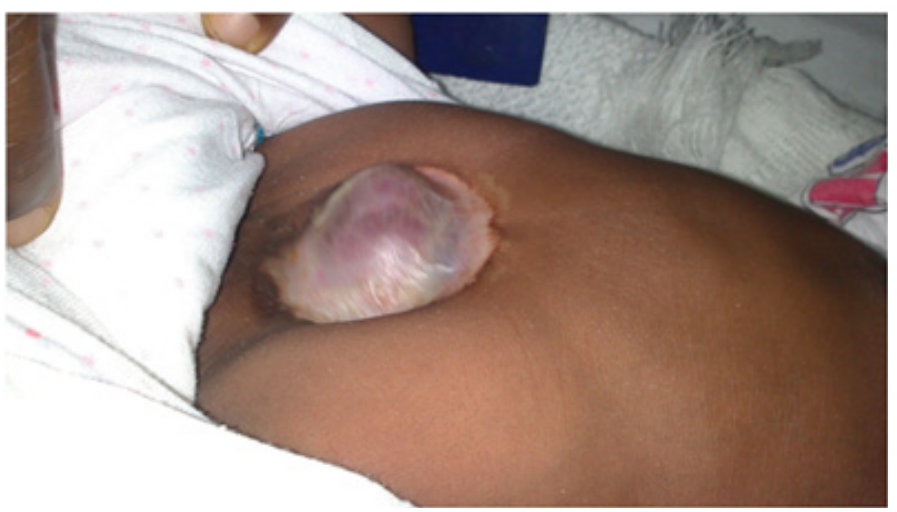

Figure I Defect over the manubro-sternum exposing a pulsating heart covered by pericardium. 
Initial treatment included daily dressing of the exposed defect with saline gauze and Sofra-Tulle. Consultations of various specialists including the Paediatric Cardiologist, Cardiothoracic Surgeons, Burns and Plastic Surgeons and Anaesthetists were made. She tolerated breast feeding. On the second day of admission she developed a fever and intravenous antibiotics were commenced. The fever resolved within 48 hours and the patient remained clinically stable. Surgery was planned for immediately but it was delayed on account of financial constraints of her parents. Surgery was done after four weeks on admission by the Plastic surgeons and Cardiothoracic Surgeons.

Operative findings were that of a central ectopia cordis with absence of the manubrium, sternum and costal cartilages of the ribs 1-5 with an exposed pericardium. After the surgery, the plan was to move the patient to a Paediatric Intensive Care Unit, but for lack of a Paediatric ventilator she was moved to the neonatal ward where she was monitored by the surgical team, Paediatric Cardiologist and Neonatologists. Post-operative care included intravenous antibiotics, intravenous fluid and supplemental oxygen. The patient remained stable during the adjoining post-operative days with normal oxygen saturation. However on the fourth post-operative day, there was purulent discharge from the operation site. Microscopy culture and sensitivity yielded klebsiella aerogenes. Antibiotics were changed according to the sensitivity pattern. Following the infection at the operation site, there was dehiscence of the wound exposing the mesh completely and the heart was seen pulsating underneath the mesh With judicious use of antibiotics and daily dressings of the operation site, the infection was well controlled. She remained stable clinically. There was gradual re-epithelialization of the wound from the edges and under the mesh. She was discharged home nine weeks after the mesh repair of the defect. She was to present on alternate days to the hospital for dressing of the wound. At discharge from the hospital, there was a clean granulation tissue with progressive coverage over the exposed pericardium. Only a minimal defect was left.

She kept a regular follow up visits where the wound was dressed. There was complete epithelialization of the wound and a thick covering completely covered the pericardium. Two months later, the mesh was completely extruded. The plan was for a reconstruction surgery for apposition of the skin. She was readmitted five weeks after her last clinic visit on account of a three days history of fever and one day history of repeated convulsions. On examination at presentation, she was febrile $(40.10 \mathrm{C})$, pale, in respiratory distress, desaturating in room air, acyanosed and anicteric. She was also, tachypneic, tachycardic, and lethargic with a bulging anterior fontanelle. A presumptive diagnosis of septicaemia with meningitis was made and the necessary investigations requested. Intravenous antibiotics were commenced immediately. Unfortunately she succumbed within 12 hours of readmission. She was seven months old at her demise.

\section{Discussion}

Thoracic ectopia cordis is the most common form of ectopia cordis, accounting for $65 \%$ of all case of ectopia cordis. ${ }^{7}$ Other subtypes of ectopia cordis includes, cervical, cervico-thoracic and abdominothoracic and abdominal. ${ }^{1,3}$ Thoracic and indeed all other subtypes of ectopia cordis have been reported in various regions of the world. The incidence of thoracic ectopia cordis is 5.7-7.9 per million live births in the USA. ${ }^{4}$ The incidence is not known in Africa but various authors have reported cases in the sub-region. ${ }^{8}$ Ectopia cordis may be associated with other intra- and extra-cardiac anomalies. Some extra-cardiac anomalies that may be associated with it includes abdominal wall defects, cranial and facial abnormalities, cleft lip and palate, anencephaly, hydrocephalus, neural tube defects, pulmonary hypoplasia and chromosomal abnormalities such as trisomy 18 and Turners syndrome. ${ }^{9}$ The index patient did not have any associated anomalies.

Diagnosis of the ectopia cordis may be made in-utero from the second trimester of pregnancy. ${ }^{9}$ Fetal echocardiograph will reveal any associated cardiac anomaly. In the present report, a prenatal ultrasound scan was done in pregnancy at a private facility and the diagnosis was missed. The ultrasound scan was done in the first trimester and the diagnosis was missed probably because of the timing of the sonography. Given the high mortality rate associated with the ectopia cordis, therapeutic abortion prior to the age of viability may be considered. ${ }^{3}$ In settings where this is not possible then a careful search for other associated anomalies is done. Treatment options are limited because the condition is generally uncommon with few survivors even after surgery.

The prognosis of the ectopia cordis depends on the location of the heart, extent of intra-cardiac defects and associated anomalies. ${ }^{1,3}$ Cervical, complete thoracic, and abdominothoracic forms have poorer outcomes compared with partial thoracic subtype. In the same light, presence of associated intra-cardiac and extra-cardiac defects are associated with poorer outcomes. Causes of death includes hypoxia, cardiac failure and infection. Although the index case survived the surgery, she succumbed year later from infections. The previous report on ectopia cordis in Nigeria was two decades ago. ${ }^{10}$ The similarity between both studies is that both cases were female infants. While the earlier case was an ectopia cordis with associated omphalocele and intra-cardiac anomaly, the present case is an isolated thoracic ectopia cordis without an extra-cardiac anomaly and a small PDA and Foramen ovale. The patient in the earlier report died within the first 72 hours of life while the index case died at seven month of age. A possible reason that may have been responsible for prolonged survival in the index case compared with the earlier study may because the patient in the earlier report had other extra-cardia and intra-cardiac anomaly.

\section{Conclusion}

In conclusion, thoracic ectopia is a rare disorder worldwide. Mortality from this condition is high. Prenatal ultrasound screening and fetal echocardiography can detect cases in-utero and further management plans instituted promptly.

\section{Consent}

Informed consent was obtained from the parents. The authors declare that no patient data appeared in this write-up.

\section{Acknowledgments}

The parent and healthcare staff who participated in the care of this patient are acknowledged.

\section{Conflicts of interest}

Author declares there are no conflicts of interest.

\section{Funding}

None.

\section{References}

1. Ectopia cordis [Internet]. [cited. 2015 Jun 12]. Available from: http.// allhealthsite.com/ectopia-cordis.html 
2. Perlstein D, Stoppler MC. Ectopia Cordis [Internet]. 2012 [cited 2015 Jun 11]. Available from: medicinenet.com/script/main/art. asp?articlekey $=155253$

3. Taksande A, Vilhekar K. A case report of ectopia cordis and omphalocele. India J Hum Genet. 2013;19(4):491-413.

4. Hornberger LK, Colan SD, Lock JE, et al. Outcome of patients with ectopia cordis and significant intracardiac defects. Circulation. 1996;94(9 Suppl):II32-II37.

5. Sadler TW. The embryologic origin of ventral body wall defects. Semin Pediatr Surg . 2010;19(3):209-214
6. Puvabanditsin S, Di Stefano V, Garrow E, et al. Ectopia cordis. Hong Kong Med J. 2013;19(5):447-450.

7. Byron F. Ectopia cordis: report of a case with attempted operative correction. J Thorac Surg. 1948;17(5):717-722.

8. Ucima N, Tuka DD, Kimbongila MM, et al. Rare Occurrence of Ectopia Cordis in a Congolese Neonate. Pediatr Neonatol. 2015;56(2):132-133.

9. Diaz JH. Perioperative management of neonatal ectopia cordis: report of three cases. Anest Analg. 1922;75(5):833-837.

10. Adebo OA, Arowolo FA, Osinowo O, et al. Ectopia cordis in a Nigerian child. West Afri J Med. 2013;12(4):233-235. 